\title{
The impact of phased university reopenings on mitigating the spread of COVID-19: a modeling study
}

\author{
Lior Rennert $^{{ }^{*}} \mathbb{D}$, Corey A. Kalbaugh ${ }^{1}$, Christopher McMahan², Lu Shi ${ }^{1}$ and Christopher C. Colenda ${ }^{3}$
}

\begin{abstract}
Background: Several American universities have experienced COVID-19 outbreaks, risking the health of their students, employees, and local communities. Such large outbreaks have drained university resources and forced several institutions to shift to remote learning and send students home, further contributing to community disease spread. Many of these outbreaks can be attributed to the large numbers of active infections returning to campus, alongside high-density social events that typically take place at the semester start. In the absence of effective mitigation measures (e.g., high-frequency testing), a phased return of students to campus is a practical intervention to minimize the student population size and density early in the semester, reduce outbreaks, preserve institutional resources, and ultimately help mitigate disease spread in communities.
\end{abstract}

Methods: We develop dynamic compartmental SARS-CoV-2 transmission models to assess the impact of a phased reopening, in conjunction with pre-arrival testing, on minimizing on-campus outbreaks and preserving university resources (measured by isolation bed capacity). We assumed an on-campus population of $N=7500,40 \%$ of infected students require isolation, 10 day isolation period, pre-arrival testing removes $90 \%$ of incoming infections, and that phased reopening returns one-third of the student population to campus each month. We vary the disease reproductive number $\left(R_{t}\right)$ between 1.5 and 3.5 to represent the effectiveness of alternative mitigation strategies throughout the semester.

Results: Compared to pre-arrival testing only or neither intervention, phased reopening with pre-arrival testing reduced peak active infections by 3 and 22\% ( $\left.R_{t}=1.5\right), 22$ and 29\% $\left(R_{t}=2.5\right), 41$ and $45 \%\left(R_{t}=3.5\right)$, and 54 and $58 \%$ (improving $R_{t}$ ), respectively. Required isolation bed capacity decreased between 20 and $57 \%$ for values of $R_{t} \geq 2.5$.

Conclusion: Unless highly effective mitigation measures are in place, a reopening with pre-arrival testing substantially reduces peak number of active infections throughout the semester and preserves university resources compared to the simultaneous return of all students to campus. Phased reopenings allow institutions to ensure sufficient resources are in place, improve disease mitigation strategies, or if needed, preemptively move online before the return of additional students to campus, thus preventing unnecessary harm to students, institutional faculty and staff, and local communities.

Keywords: COVID-19, SARS-CoV-2, Testing, Mitigation, Students, University, Phased return, Modeling

\footnotetext{
*Correspondence: liorr@clemson.edu

'Department of Public Health Sciences, Clemson University, 529 Edwards

Hall, Clemson, SC, USA

Full list of author information is available at the end of the article
}

(c) The Author(s). 2021 Open Access This article is licensed under a Creative Commons Attribution 4.0 International License, which permits use, sharing, adaptation, distribution and reproduction in any medium or format, as long as you give appropriate credit to the original author(s) and the source, provide a link to the Creative Commons licence, and indicate if changes were made. The images or other third party material in this article are included in the article's Creative Commons licence, unless indicated otherwise in a credit line to the material. If material is not included in the article's Creative Commons licence and your intended use is not permitted by statutory regulation or exceeds the permitted use, you will need to obtain permission directly from the copyright holder. To view a copy of this licence, visit http://creativecommons.org/licenses/by/4.0/ The Creative Commons Public Domain Dedication waiver (http://creativecommons.org/publicdomain/zero/1.0/) applies to the data made available in this article, unless otherwise stated in a credit line to the data. 


\section{Background}

Higher education institutions are struggling to reopen their campuses in a safe and judicious manner during the Coronavirus disease 2019 (COVID-19) pandemic. The reopening strategies for Fall 2020 implemented by several major universities in the United States have been largely unsuccessful [1]. Other institutions have elected to delay reopening, partially reopen, or remain closed, preferring instead to continue with online instruction [2-4]. Those planning to continue with reopening are exploring several preventative strategies to mitigate the spread of severe acute respiratory syndrome coronavirus 2 (SARS-CoV-2), including frequent testing, contact tracing, and isolation of confirmed and suspected cases [5, 6].

Controlling campus outbreaks is essential for both student and community health. As of March 2nd, 2020, American colleges and universities have reported more than 535,000 cases since reopening [7]. While this population has reported a relatively low mortality rate compared to the general population, such large outbreaks will lead to a large number of symptomatic students who may be at substantial risk for post-acute COVID [8]. Outbreaks on campus will also inevitably lead to a mass increase in infections among faculty, staff, and local communities [1]. A recent modeling study found that reopening American college and university campuses may lead to an additional 820 community infections for every 10,000 residents throughout the semester [9].

One of the first steps to preventing large outbreaks is minimizing the number of infectious students returning to campus. Previous modeling studies have demonstrated that high numbers of active infections at the beginning of the semester lead to early and large outbreaks and drain institutional resources [10]. This has been further evidenced by recent COVID-19 outbreaks in major universities, [1] which have been forced to send students home and shift to online learning within 1 week of reopening $[11,12]$. With such early outbreaks and closures, implementation of preventative strategies throughout the semester may no longer be relevant, as these strategies are intended to prevent outbreaks rather than contain them. Indeed, the initial number of active infections assumed by modeling studies that support these strategies $[13,14]$ may be far lower than suggested by current estimates of SARS-CoV-2 prevalence and recent university reopenings $[11,12]$. Contact tracing, for example, has shown to be ineffective when the number of initial infections is greater than 40 [13]. Colleges and universities intending to reopen campuses in future semesters must therefore place a greater emphasis on reducing active infections and limiting outbreaks at the semester start [1]. However, between the large number of students who live in congregate housing [1] and the number of high-density social gatherings that occur early in the semester and beyond, [11, 15, 16] such outbreaks may be difficult to contain with the simultaneous return of all students to campus [17]. While evidence shows that high-frequency repeated testing is effective in mitigating disease spread on college and university campuses, $[5,18]$ many institutions lack the testing capacity necessary for implementation [19]. In the absence of such testing, alternative strategies for disease mitigation are needed.

A phased return of students to campus is a practical intervention to limit early outbreaks, ensure proper protocols are in place, and preserve university resources. This is accomplished through minimizing the susceptible population size and density early in the semester, which can delay large outbreaks and reduce outbreak size, ensure the availability of sufficient resources by vacating a large portion of isolation beds for confirmed or suspected cases, and increase testing and support service capacity per student. Furthermore, a phased reopening provides institutions time to improve strategies to mitigate the spread of COVID-19 (e.g., frequent testing [1]) and adjust for factors that drive outbreaks (e.g., fraternity gatherings $[11,15,16])$ before the return of additional students to campus. If outbreaks cannot be contained, a phased reopening allows higher education institutions to pre-emptively transition to remote learning before the arrival of all students and thus prevent unneccessary harm to students, faculty and staff, and local communities.

Our team was tasked with recommending strategies to limit outbreaks and ensure adequate resources are in place for confirmed COVID-19 cases in a large university in the Southeastern United States during the Fall 2020 semester. To guide and inform our recommendations, we developed dynamic compartmental transmission models to assess the impact of a phased reopening, along with exclusion of COVID-19 positive students through testing prior to campus arrival, on minimizing outbreak size and preserving university resources throughout the semester. Preservation of university resources is important to ensure adequate student care and limit community spread. Without sufficient resources, such as isolation beds, universities may be forced to send students home which may increase disease spread in their home communities [20].

\section{Methods}

To capture the essential features of COVID-19 spread on campus, we developed dynamic compartmental transmission models of SARS-COV-2 [21] with the following compartments: susceptible, exposed, infectious.

(asymptomatic/undetected), infectious (symptomatic/ detected), isolated, and recovered (Fig. 1). We assumed a 


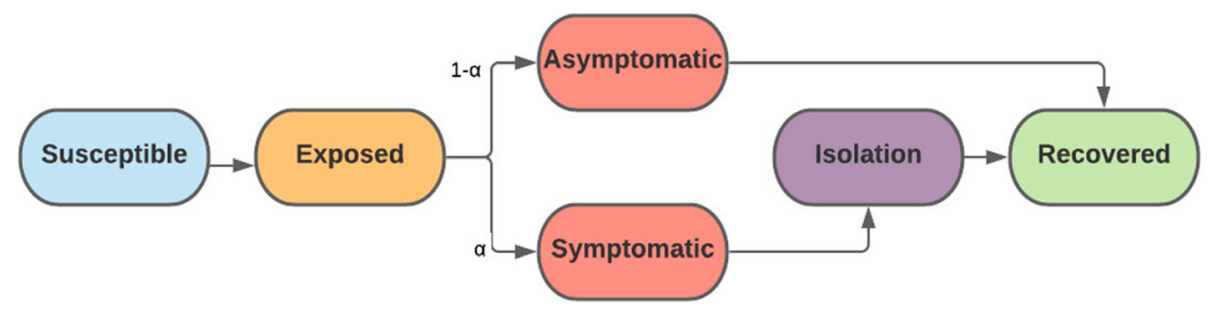

Fig. 1 Model structure. The population is divided into the following six compartments: susceptible, exposed (not infectious or detectable), asymptomatic (infectious and not detectable), symptomatic (infectious and detectable), isolated (no contact with other individuals), and recovered. Exposed individuals transition into the symptomatic compartment with probability a and asymptomatic compartment with probability 1-a. It is assumed all symptomatic individuals are detected (after an average period of 3 days) and isolated for the remaining duration of their infection

large on-campus population $(N=7500)$, an active infection rate of $3 \%$ at the semester start, [18] and that $40 \%$ of active infections would be detected [18] and require isolation for an average period of 10 days [22]. We considered four settings for the reproductive number $\left(R_{t}\right)$ to represent the effectiveness of various mitigation strategies throughout the semester: highly effective $\left(R_{t}=1.5\right)$, moderately effective $\left(R_{t}=2.5\right)$, and ineffective $\left(R_{t}=3.5\right)$, [5] along with a time-varying $R_{t}$ that improved throughout the semester $\left(R_{0}=3.5, R_{1}=2.5\right.$, and $R_{t}=1.5$ for months $t \geq 2$ ). In the former setting, we assume that $R_{t}=$ $R_{0}$ for all $t \geq 0$. The latter setting was intended to capture improvement in mitigation efforts over time, such as an increase in testing capabilities or greater enforcement of mask mandates. Additional assumptions were compiled from published sources and are provided in Table 1. Because this study used only a theoretical model with no human subject data, the Institutional Review Board of Clemson University determined that this research did not involve human participants and did not require their approval.

We considered three interventions: Phased reopening with pre-arrival testing, pre-arrival testing only, and neither intervention. We assumed that pre-arrival testing reduced the number incoming infections by $90 \%[5,25]$. To reduce model complexity, COVID-19 positive individuals detected through pre-arrival testing immediately entered the isolation compartment and undetected infections entered the asymptomatic and symptomatic infectious compartments (according to $\alpha$ parameter in Table 1). We assumed a phased re-opening over a 2month period, in which one-third of the population (2500 students) returned to campus at the semester start, 30 days after the semester start, and 60 days after the semester start. We further assumed that the disease reproductive rate is reduced by $20 \%$ during the first phase and 10\% during the second phase due to a decrease in student population density, and that any unoccupied beds during these phases are available for isolation of detected COVID-19 cases. The baseline infection rate for incoming students was held constant at
$3 \%$ in all phases. The equations and initial values for each compartment are provided in Supplementary Table 1.

We evaluated the relative impact of each intervention on the number of active infections throughout the semester (daily, peak, total) and isolation bed capacity. At each timepoint $t$, active infections was defined as the number of currently infected students (i.e., sum of asymptomatic, symptomatic, and isolation compartments at time $t$ ). Peak active infections was defined as the maximum number of daily active infections. Isolation bed capacity was measured as the number of oncampus beds needed for isolation throughout the semester $\left(n_{\text {beds }}\right)$ and as the proportion relative to the oncampus population size $\left(n_{\text {beds }} / N\right)$. In the Supplementary Analyses, we explore the relative impact of a phased reopening on infections and isolation bed capacity under several scenarios: 1) Higher proportion of asymptomatic individuals, 2) decreased test sensitivity at the semester start, 3) larger student immunity at the semester start, 4) shorter time periods between phases and 5) faster implementation of effective mitigation measures. A publicly accessible version of the model implementation is available online (https://rennertl.shinyapps.io/ phasedreopeningprojections).

\section{Results}

The number of active infections throughout the semester based on the model projections are displayed in Fig. 2. In all scenarios, both pre-arrival testing alone and in conjunction with phased reopening reduced the rate of active infections early in the semester and delayed the timing of the peak outbreak size. Summary statistics are displayed in Table 2. A phased reopening in conjunction with pre-arrival testing reduced the size of the peak outbreak across all scenarios. Under highly effective mitigation strategies throughout the semester $\left(R_{t}=1.5\right)$, a phased reopening reduced peak outbreak size by 3 and $22 \%$ compared to pre-arrival testing only and no interventions, respectively. For moderate to ineffective mitigation strategies throughout the semester, this decrease 
Table 1 Model input parameters, assumptions, and references

\begin{tabular}{|c|c|}
\hline Model parameter & Input \\
\hline On-campus population (N) & 7500 (assumption) \\
\hline Time horizon (weeks) & 18 weeks \\
\hline \multicolumn{2}{|l|}{ Disease dynamics ${ }^{\text {a }}$} \\
\hline Mean incubation time, $1 / \sigma$ & 3 days [23] \\
\hline Mean asymptomatic infectious time (days), $1 / \varphi$ & 10 days [22] \\
\hline $\begin{array}{l}\text { Mean symptomatic infection time before detection } \\
\text { and isolation (days), } 1 / \gamma\end{array}$ & $\begin{array}{l}3 \text { days (accounting for 2-day pre-symptomatic period } \\
\text { and 1-day test turnaround time) [23] }\end{array}$ \\
\hline Isolation time, $1 / \rho$ (days) & 10 days [22] \\
\hline Proportion of infections that are symptomatic, a & $0.4[18]$ \\
\hline Transmission rate, $\beta$ & Dependent on $R_{t}$ \\
\hline Baseline infectious rate (\%) ${ }^{b}$ & $3 \%[18]$ \\
\hline Baseline recovered rate (\%) & $10 \%[10,14,24]$ \\
\hline \multicolumn{2}{|l|}{ Mitigation strategies throughout semester $\left(R_{t}\right)^{c}$} \\
\hline Highly effective (best case) & $1.5[5]$ \\
\hline Moderately effective (base case) & $2.5[5]$ \\
\hline Ineffective (worst case) & $3.5[5]$ \\
\hline Time-varying & $\begin{array}{l}\text { Month 0: 4; Month 1: 2.5; Month 2+: } 1.25 \\
\text { (assumption) }\end{array}$ \\
\hline \multicolumn{2}{|l|}{ Interventions } \\
\hline \multicolumn{2}{|l|}{ Test characteristics } \\
\hline Sensitivity (\%) & $90 \%[5,25]$ \\
\hline Specificity (\%) & 100\% (assumption) \\
\hline \multicolumn{2}{|l|}{ Phased re-opening } \\
\hline Phase 1: Calendar time (months)/sub-population returning to campus & 0 months/2500 students (assumption) \\
\hline $\begin{array}{l}\text { Phase 2: Calendar time (months)/sub-population returning to campus/cumulative } \\
\text { population }\end{array}$ & 1 months/2500 students/5000 students (assumption) \\
\hline $\begin{array}{l}\text { Phase 3: Calendar time (months)/sub-population returning to campus/cumulative } \\
\text { population }\end{array}$ & 2 months/2500 students/7500 students (assumption) \\
\hline
\end{tabular}

a We assume a closed system (i.e., no exogenous infections or deaths)

${ }^{b}$ Under pre-arrival testing, baseline infections are reduced by $90 \%$

c Under phased reopening, we assume this number is reduced by $20 \%$ during the first phase and $10 \%$ during the second phase

was substantial. Compared to the simultaneous return of all students, a phased reopening (with pre-arrival testing) decreased the peak number of active infections between 22 to $29 \%\left(R_{t}=2.5\right)$ and 41 to $45 \%\left(R_{t}=3.5\right)$. Under improving mitigation strategies throughout the semester ( $R_{0}=3.5, R_{1}=2.5$, and $R_{t}=1.5$ for $t \geq 2$ months), phased reopening with pre-arrival testing decreased the peak number of active infections between 54 to $58 \%$. Under effective $\left(R_{t}=1.5\right)$ and improving mitigation strategies, a phased return of students to campus reduced total infections by 22 and $28 \%$ throughout the semester. The relative decrease under moderate $\left(R_{t}=2.5\right)$ and infective $\left(R_{t}=3.5\right)$ mitigation measures was between 2 and 5\%. Compared to no interventions, pre-arrival testing alone reduced peak active infections between 6 and 20\% and reduced total infections between 0.2 and $8 \%$ across all scenarios.
Pre-arrival testing alone had minimal impact on maximum isolation bed capacity, while implementation in conjunction with a phased reopening substantially reduced the number of isolation beds needed for values of $R_{t} \geq 2.5$ (Table 2). Under $R_{t}=2.5$, phased reopening with pre-arrival testing required $6.8 \%$ of beds reserved for isolation of symptomatic/detected students, a 20 to $27 \%$ reduction compared to pre-arrival testing only and no interventions, respectively. Under $R_{t}=3.5$ and improving $R_{t}$, phased reopening in conjunction with pre-arrival testing required 5.3 to $5.5 \%$ of beds reserved for isolation of symptomatic students - a 52 to $57 \%$ decrease compared to the two other strategies. .

\section{Discussion}

Minimizing the number of active infections at the semester start is essential to limiting rapid outbreaks and ensuring sufficient resources are available for support 


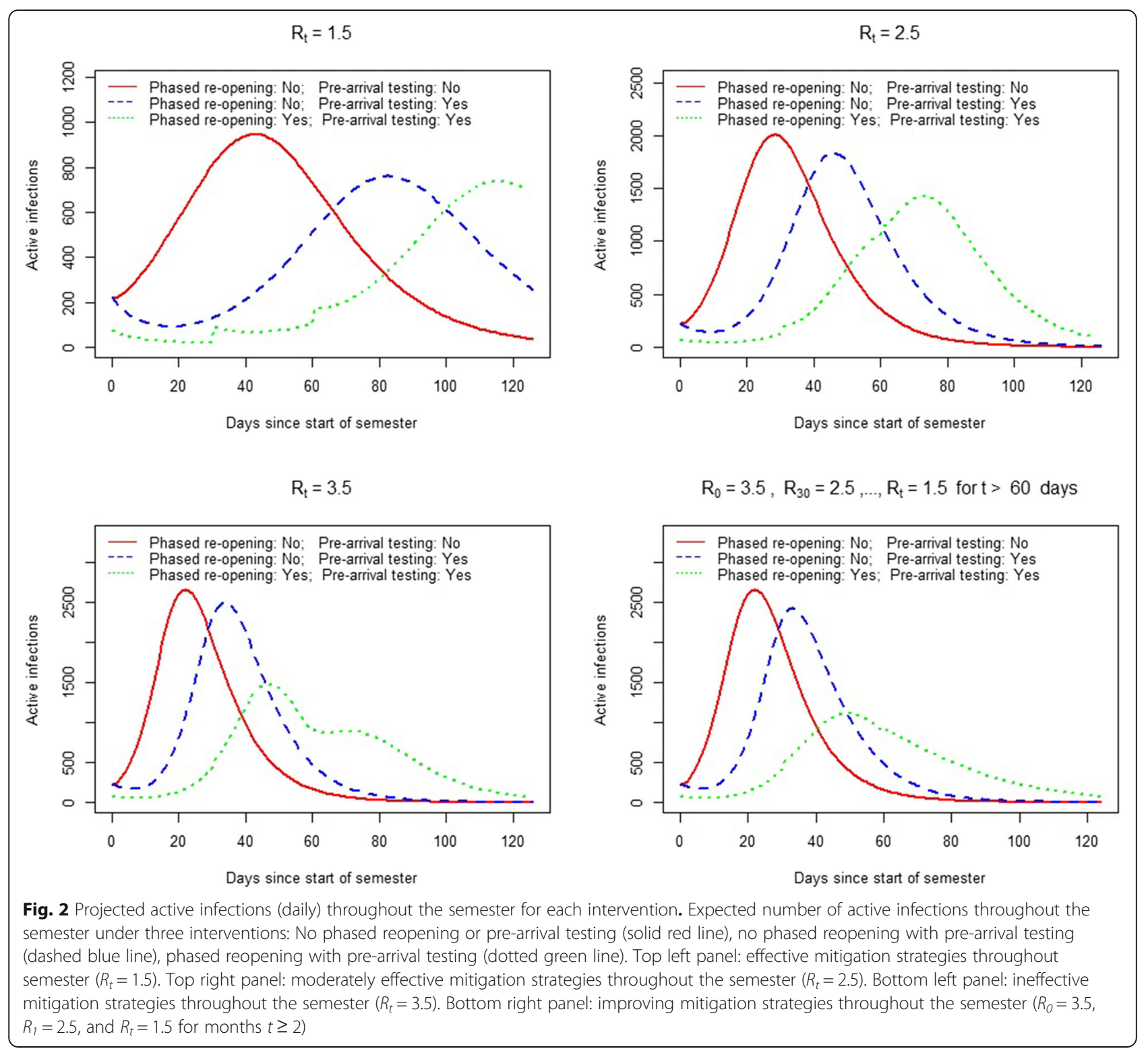

services such as testing, contact tracing, and case isolation. Universities implementing frequent SARS-CoV-2 testing have been relatively successful in detecting and containing outbreaks $[18,26]$. However, most universities did not regularly test their students during the Fall 2020 semester [19]. Our study found that unless highly effective mitigation strategies are implemented, such as frequent testing, the simultaneous arrival of all students to campus leads to early and large outbreaks. Furthermore, the timing of these outbreaks occur early in the semester and are therefore not impacted by improvements in mitigation efforts over time. Our modeling study concluded that a phased return of students to campus in conjunction with testing prior to arrival substantially delays the peak outbreak timing and reduces the outbreak size by up to $58 \%$.
Rapid outbreaks drain university resources and have lead to institutions shutting down on-campus activities and shifting fully online [1]. Our models demonstrate that the simultaneous return of all students to campus may require reservation of over $10 \%$ of on-campus beds for isolation of detected COVID-19 cases, far exceeding the current capacity of several large institutions $[27,28]$. In fact, we found that the recommended $5 \%$ of isolation beds for confirmed COVID-19 cases [29] may lead to institutions reaching capacity in less than 2 weeks. Under a phased reopening with pre-arrival testing, the number of isolation beds needed ranged from 3.5 to $6.8 \%$ of total capacity. A phased return would further decrease the number of beds needed if students testing positive prior to arrival stayed at home rather than occupying a university-provided isolation bed. 
Table 2 Outcome metrics based on modeling study under each strategy across varying disease reproductive numbers

\begin{tabular}{|c|c|c|c|c|c|}
\hline \multirow[t]{2}{*}{ Phased reopening } & \multirow[t]{2}{*}{ Pre-arrival testing } & \multicolumn{4}{|c|}{ Peak outbreak: size (days to peak) } \\
\hline & & $R_{t}=1.5$ & $R_{t}=2.5$ & $R_{t}=3.5$ & $R_{t}=3.5,2.5,1.5^{a}$ \\
\hline No & No & 948 (42 days) & 2014 (28 days) & 2660 (22 days) & 2660 (22 days) \\
\hline No & Yes & 760 (82 days) & 1837 (46 days) & 2495 (34 days) & 2422 (33 days) \\
\hline \multirow[t]{3}{*}{ Yes } & Yes & 738 (115 days) & 1430 (73 days) & 1476 (47 days) $^{b}$ & 1111 (49 days) $^{\mathrm{b}}$ \\
\hline & & \multicolumn{4}{|c|}{ Total infections } \\
\hline & & $R_{t}=1.5$ & $R_{t}=2.5$ & $R_{t}=3.5$ & $R_{t}=3.5,2.5,1.5^{a}$ \\
\hline No & No & 4974 & 6192 & 6438 & 6394 \\
\hline No & Yes & 4562 & 6151 & 6425 & 6261 \\
\hline \multirow[t]{3}{*}{ Yes } & Yes & 3558 & 6010 & 6100 & 4856 \\
\hline & & \multicolumn{4}{|c|}{ Beds needed for isolation of detected individuals: $n_{\text {beds }}(\%)^{c}$} \\
\hline & & $R_{t}=1.5$ & $R_{t}=2.5$ & $R_{t}=3.5$ & $R_{t}=3.5,2.5,1.5^{\mathrm{a}}$ \\
\hline No & No & $336(4.5 \%)$ & $704(9.4 \%)$ & $916(12.2 \%)$ & $916(12.2 \%)$ \\
\hline No & Yes & $270(3.6 \%)$ & $643(8.6 \%)$ & $863(11.5 \%)$ & $834(11.1 \%)$ \\
\hline Yes & Yes & $263(3.5 \%)$ & $513(6.8 \%)$ & $415(5.5 \%)$ & $397(5.3 \%)$ \\
\hline
\end{tabular}

Outcome metrics are peak outbreak size (and days to peak outbreak size), total infections, and isolation beds capacity for detected students throughout the semester under three interventions: No phased reopening or pre-arrival testing, pre-arrival testing only, phased re-opening with pre-arrival testing. The size of the on-campus student population is $N=7500$

${ }^{a}$ Improving $R_{t}: R_{0}=3.5, R_{1}=2.5$, and $R_{t}=1.5$ for months $t \geq 2$

${ }^{b}$ Peak outbreak occurred with $2 / 3^{\prime}$ s of student population on campus (i.e, 5000 students) ${ }^{\mathrm{c}}$ Proportion of isolation beds needed ( $n_{\text {beds }}$ ) relative to on-campus student population $(N)$

Phased reopenings are practical interventions that can be implemented in various ways. During the Fall 2020 semester, Clemson University phased the return of students to campus by beginning the semester entirely online and delaying in-person instruction by 1 month [18]. The phased return of off-campus students did not require explicit interventions since these students (roughly two-thirds of the undergraduate population) were either already living off campus at the start of summer 2020, or gradually moved off-campus throughout the summer months as new leases were enacted. However, delaying in-person instruction and access to residential buildings by 1 month ensured that residential and non-residential students would not simultaneously arrive to campus or the immediate off-campus area. Furthermore, the return of residential students to campus was distributed over a 10-day period to further decrease the risk of outbreaks. We note that the phased return of students to campus was only applied during the Fall semester when a large portion of the population was susceptible to infection. As more of the population builds immunity through natural infection, [30] the relative impact of a phased a student return on disease mitigation is less substantial.

Based on mandatory pre-arrival and survellance testing throughout the Fall 2020 semester, there is evidence that infections among off-campus students reached their peak during the summer months of 2020 and thus prior to in-person instruction [18]. On the other hand, peak infection among on-campus students occurred in during in-person instruction of the fall semester [18].
Approximately 620 of the 800 reserved isolation beds were in use following the peak infection period. If both on- and off-campus populations had returned to the campus area simultaneously, it is possible that peak infection would have been greater among on-campus students (due to increased transmission from off-campus students) and may have forced the university to suspend or shut down operations for the remainder of the semester.

Our study has several limitations. First, we omit an indepth discussion of the logistics behind a phased reopening. Difficulties in implementation include the careful coordination of the return of students back to campus and may require institutions to shift between on-campus and remote learning throughout the phased reopening. The costs of unutilized institutional facilities are also not considered here. In addition, our study does not consider the contribution of off-campus students to the spread of COVID-19, and we do not explicitly model the impact of a phased reopening on community spread. As empirical data becomes available, future research must examine the impact of university outbreaks in local communities along with the impact of university-level interventions on mitigating disease spread in these communities.

Another limitation is that we provide estimates for isolation bed capacity of detected students only. The total number of beds needed to be reserved by institutions must also account for quarantining close contacts of detected positive individuals [31]. Therefore, the numbers 
presented here are likely underestimating the true number of reserved beds needed. Furthermore, if institutions implement surveillance testing, additional beds would be needed for asymptomatic cases. However, the total number of required beds may ultimately be lower if frequent testing was employed [5].

While we used current evidence to inform plausible biological parameters for SARS-CoV-2 transmission, these values may need refinement as more data become available (e.g., differing transmission rates between asymptomatic and symptomatic individuals) [32]. To assess sensitivity to model assumptions, we varied disease transmission parameters in order to provide a range of possible outcomes. While the effects of mitigation strategies throughout the semester, such as frequent testing, successful contact tracing, and quarantine of suspected cases are implicitly incorporated into our model through the reproductive number $\left(R_{t}\right)$, we do not consider the impact of these strategies on isolation bed occupancy. Finally, this study only considers a single phased reopening strategy (i.e., monthly return of one-third of student population). We have therefore created a free web-based application to allow for the exploration of alternative strategies under varying parameter values (available at: https://rennertl.shinyapps.io/phasedreopeningprojections/).

\section{Conclusions}

As colleges and universities across the United States plan a return to normal campus life in the Fall 2021 semester, [33] we encourge institutions to ensure a sufficient supply of isolation beds and support service capacity. This is necessary to guarantee adequate student care and limit downstream effects on communities across the country. In addition, all students should be tested prior to campus arrival to avoid the return of active infections to campus. A phased reopening offers several additional benefits. Limiting the number of students on-campus at the start of the semester can substantially reduce the number of initial infections and delay the timing and size of outbreaks, while providing opportunities to improve safety protocols and adjust for factors that drive these outbreaks before the return of additional students to campus. Furthermore, minimizing the size of the susceptible population will help ensure that institutions have sufficient resources at their disposal to handle early outbreaks. A phased reopening also provides opportunities to trial mitigation strategies on a smaller population before they are implemented in larger scales. Most importantly, if COVID-19 outbreaks cannot be kept under control with a limited student population, phased reopenings provide the ability to halt the return of additional students to campus and prevent thousands of additional infections, thus preventing unnecessary harm to students, institutional faculty and staff, and local communities.
Abbreviations

Covid-19: Coronavirus disease 2019; SARS-CoV-2: Severe acute respiratory syndrome coronavirus 2

\section{Supplementary Information}

The online version contains supplementary material available at https://doi org/10.1186/s12889-021-11525-x.

Additional file 1: Supplementary Table 1. Equations and initial values for dynamic compartmental transmission models.

Additional file 2: Supplementary Fig. 1. Increasing the proportion of asymptomatic students to $75 \%$. Supplementary Fig. 2. Decreasing prearrival test sensitivity to $70 \%$. Supplementary Fig. 3. Increasing proportion of immune individuals at the semester start to $25 \%$. Supplementary Fig. 4. Decreasing time between phases to 10 days. Supplementary Fig. 5. Improving $R_{t}$ under settings in Supplementary Fig. 4.

\section{Acknowledgements}

We thank the reviewers for their valuable feedback and suggestions.

\section{Authors' contributions}

LR: Conceptualization, literature search, figures, methodology, writing, review, and editing; CAK: Project administration, writing, review, and editing; CM: Methodology, review, and editing; LS: Review and editing, literature search; CCC: Conceptualization, literature search, writing, review, and editing. All authors have read and approved the final manuscript.

\section{Funding}

LR, CAK, CM, and LS acknowledge salary support from Clemson University for modeling work pertaining to reopening strategies (project \#1502934). CCC is an independent paid advisor to Clemson University on COVID-19 matters.

\section{Availability of data and materials}

No data was collected for this study. A publicly accessible version of the model implementation is available online (https://rennertl.shinyapps.io/ phasedreopeningprojections). Data sources that support our choice for model parameters are provided in Table 1.

\section{Declarations}

Ethics approval and consent to participate Not applicable.

\section{Consent for publication}

Not applicable.

\section{Competing interests}

LR, CAK, CM, and LS acknowledge salary support from Clemson University for modeling work pertaining to reopening strategies. CCC is an independent paid advisor to Clemson University on COVID-19 matters. Clemson University did not influence our work or findings. The funders of this study had no role in the study design or data collection, including model assumptions and choice of model parameters, or interpretation of results and writing of the report. The corresponding author had full access to all data used in this study and had final responsibility for all aspects of this study, including the decision to submit for publication.

\section{Author details}

'Department of Public Health Sciences, Clemson University, 529 Edwards Hall, Clemson, SC, USA. ${ }^{2}$ School of Mathematical and Statistical Sciences, Clemson University, Clemson, SC, USA. ${ }^{3}$ Department of Internal Medicine, Section of Gerontology and Geriatrics, Wake Forest University, Winston-Salem, NC, USA. 
Received: 21 October 2020 Accepted: 20 July 2021

Published online: 06 August 2021

\section{References}

1. Yamey G, Walensky R P. Covid-19: re-opening universities is high risk BMJ. 2020;370:m3365. https://doi.org/10.1136/bmj.m3365.

2. IHE Staff. COVID-19 roundup: Pitt and Drexel extend remote instruction; Congress scrutinizes colleges and student housing company. Inside Higher Ed. 2020; [cited 2020 Aug 22] Available from: https://www.insidehighered. com/news/2020/08/20/covid-19-roundup-pitt-and-drexel-extend-remoteinstruction-congress-scrutinizes.

3. The Associated Press. As More Colleges Stay Online, Students Demand Tuition Cuts. The New York Times [Internet]. 2020 Aug 22 [cited 2020 Aug 22]; Available from: https://www.nytimes.com/aponline/2020/08/22/us/apvirus-outbreak.html

4. Chronical Staff. Here's Our List of Colleges' Reopening Plans. The Chronicle of Higher Education [Internet]. 2020 Jul 29 [cited 2020 Aug 25]; Available from: https://www.chronicle.com/article/heres-a-list-of-colleges-plans-forreopening-in-the-fall/

5. Paltiel AD, Zheng A, Walensky RP. Assessment of SARS-CoV-2 screening strategies to permit the safe reopening of college campuses in the United States. JAMA Netw Open. 2020 Jul 31;3(7):e2016818. https://doi.org/10.1001/ jamanetworkopen.2020.16818.

6. Redden E. COVID-19 testing strategies vary widely across institutions. Inside Higher Ed [Internet]. 2020 Aug 21 [cited 2020 Aug 22]; Available from: https://www.insidehighered.com/news/2020/08/21/covid-19-testing-stra tegies-vary-widely-across-institutions

7. The New York Times. Tracking the Coronavirus at U.S. Colleges and Universities. The New York Times [Internet]. 2021 Mar 2 [cited 2021 Apr 19]; Available from: https://www.nytimes.com/interactive/2021/us/college-covidtracker.html

8. Quantifying asymptomatic infection and transmission of COVID-19 in New York City using observed cases, serology, and testing capacity Rahul Subramanian, Qixin He, Mercedes Pascual Proceedings of the National Academy of Sciences. 2021;118(9):2019716118. https://doi.org/10.1073/pna s.2019716118.

9. Benneyan J, Gehrke C, llies I, Nehls N. Community and Campus COVID-19 Risk Uncertainty Under University Reopening Scenarios: Model-Based Analysis. JMIR Public Health Surveill. 2021;7(4):e24292. https://doi.org/10.21 96/24292.

10. Rennert L, Kalbaugh CA, Shi L, McMahan C. Modelling the impact of presemester testing on COVID-19 outbreaks in university campuses. BMJ Open. 2020 Dec 1;10(12):e042578. https://doi.org/10.1136/bmjopen-2020042578

11. Nierenberg A, Pasick A. Colleges Closing: University Outbreaks and Parental Angst. The New York Times [Internet]. 2020 Aug 19 [cited 2020 Aug 22]; Available from: https://www.nytimes.com/2020/08/19/us/colleges-closingcovid.html

12. Svrluga S. UNC-Chapel Hill begins testing as coronavirus cases spike, while N.C. State switches to virtual classes. Washington Post [Internet]. [cited 2020 Aug 22]; Available from: https://www.washingtonpost.com/education/2020/ 08/20/nc-state-switches-virtual-classes-amid-covid-clusters-adding-scramblestudents-moving/. Accessed 22 Aug 2020

13. Hellewell J, Abbott S, Gimma A, Bosse NI, Jarvis Cl, Russell TW, et al. Feasibility of controlling COVID-19 outbreaks by isolation of cases and contacts. Lancet Glob Health. 2020 Apr 1;8(4):e488-96. https://doi.org/10.101 6/S2214-109X(20)30074-7.

14. Martin N, Schooley RT, De Gruttola V. Modelling testing frequencies required for early detection of a SARS-CoV-2 outbreak on a university campus [Internet]. Infectious Diseases (except HIV/AIDS); 2020 Jun [cited 2020 Jun 26]. Available from: http://medrxiv.org/lookup/doi/https://doi.org/1 $0.1101 / 2020.06 .01 .20118885$

15. St. Amour M. Colleges point fingers at students for partying, spreading COVID-19. Inside Higher Ed [Internet]. 2020 Aug 21 [cited 2020 Aug 22] Available from: https://www.insidehighered.com/news/2020/08/21/collegespoint-fingers-students-partying-spreading-covid-19

16. College Officials Clamp Down on Student Behavior Over Covid-19 Fears. The New York Times [Internet]. 2020 Aug 20 [cited 2020 Aug 23]; Available from: https://www.nytimes.com/2020/08/20/world/coronavirus-covid.html

17. Hubler S, Hartocollis A. Stop Campus Partying to Slow the Virus? Colleges Try but Often Fail. The New York Times [Internet]. 2020 Aug 22 [cited 2020
Aug 25]; Available from: https://www.nytimes.com/2020/08/22/us/college-ca mpus-covid.html

18. Rennert L, McMahan C, Kalbaugh CA, Yang Y, Lumsden B, Dean D, et al. Surveillance-based informative testing for detection and containment of SARS-CoV-2 outbreaks on a public university campus: an observational and modelling study. Lancet Child Adolesc Health. 2021;5(6):428-36. https://doi. org/10.1016/S2352-4642(21)00060-2.

19. Nadworny E, McMinn S. Even In COVID-19 Hot Spots, Many Colleges Aren't Aggressively Testing Students [Internet]. NPR. 2020 [cited 2020 Nov 23]. Available from: https://www.npr.org/2020/10/06/919159473/even-in-covidhot-spots-many-colleges-arent-aggressively-testing-students

20. CDC. Considerations for Institutions of Higher Education [Internet]. Centers for Disease Control and Prevention: Coronavirus Disease 2019 (COVID-19). 2020 [cited 2020 Oct 15]. Available from: https://www.cdc.gov/coronavirus/2 019-ncov/community/colleges-universities/considerations.html

21. Bjørnstad ON. Epidemics: models and data using R. Cham: Springer International Publishing; 2018 [cited 2020 Jun 28]. (Use R!). Available from: http://link.springer.com/https://doi.org/10.1007/978-3-319-97487-3

22. CDC. Duration of Isolation and Precautions for Adults with COVID-19 [Internet]. Centers for Disease Control and Prevention. 2020 [cited 2020 Dec 23]. Available from: https://www.cdc.gov/coronavirus/2019-ncov/hcp/dura tion-isolation.html

23. He X, Lau EHY, Wu P, Deng X, Wang J, Hao X, et al. Temporal dynamics in viral shedding and transmissibility of COVID-19. Nat Med. 2020 May;26(5): 672-5. https://doi.org/10.1038/s41591-020-0869-5.

24. Havers FP, Reed C, Lim T, et al. Seroprevalence of Antibodies to SARS-CoV-2 in 10 Sites in the United States, March 23-May 12, 2020. JAMA Intern Med. 2020;180(12):1576-86. https://doi.org/10.1001/jamainternmed.2020.4130.

25. Berenger BM, Fonseca K, Schneider AR, Hu J, Zelyas N. Sensitivity of nasopharyngeal, nasal and throat swab for the detection of SARS-CoV-2. medRxiv. 2020; 2020.05.05.20084889. https://doi.org/10.1101/2020.05.05.2 0084889.

26. Denny TN, Andrews L, Bonsignori M, Cavanaugh K, Datto MB, Deckard A, et al. Implementation of a pooled surveillance testing program for asymptomatic SARS-CoV-2 infections on a college campus - Duke University, Durham, North Carolina, august 2-October 11, 2020. MMWR Morb Mortal Wkly Rep. 2020;69(46):1743-7. https://doi.org/10.15585/mmwr. mm6946e1

27. Schackner B. Pitt, Penn State set aside hundreds of beds for students who might get COVID-19. Pittsburgh Post-Gazette [Internet]. [cited 2020 Aug 18] Available from: https://www.post-gazette.com/news/education/2020/07/30/ University-of-Pittsburgh-Pitt-Penn-State-fall-COVID19-football-testing-Galla gher-online/stories/202007300137. Accessed 18 Aug 2020.

28. Casagrande M. UA plans for 450 beds to isolate COVID-positive students. al [Internet]. 2020 Aug 5 [cited 2020 Aug 18]; Available from: https://www.al. com/news/2020/08/alabama-plans-for-450-beds-to-isolate-covid-positivestudents.html

29. Minnesota Department of Health. Guidance for Mitigating COVID-19 at Higher Education Institutions [Internet]. [cited 2020 Aug 18]. Available from: https://www.health.state.mn.us/diseases/coronavirus/schools/ihe.html. Accessed 18 Aug 2020.

30. Rennert L, McMahan C. Risk of SARS-CoV-2 reinfection in a university student population. Clin Infect Dis. 2021 (ciab454) [cited 2021 may 30]; Available from: https://doi.org/https://doi.org/10.1093/cid/ciab454.

31. Cui Q, Hu Z, Li Y, Han J, Teng Z, Qian J. Dynamic variations of the COVID-19 disease at different quarantine strategies in Wuhan and mainland China. J Infect Public Health. 2020;13(6):849-55. https://doi.org/10.1016/j.jiph.2020.05.014.

32. Subramanian $R, H e$ Q, Pascual M. Quantifying asymptomatic infection and transmission of COVID-19 in New York City using observed cases, serology, and testing capacityRahul Subramanian, Qixin He, Mercedes Pascual Proceedings of the National Academy of Sciences Mar. 2021;118(9): e2019716118. https://doi.org/10.1073/pnas.2019716118.

33. Kaiser Health News. Colleges and Universities Plan for Normal-ish Campus Life in the Fall [Internet]. US News \& World Report. [cited 2021 Apr 29]. Available from: //www.usnews.com/news/health-news/articles/2021-03-29/ colleges-and-universities-plan-for-partially-normal-campus-life-in-the-fall. Accessed 29 Apr 2021.

\section{Publisher's Note}

Springer Nature remains neutral with regard to jurisdictional claims in published maps and institutional affiliations. 